\title{
Introducing automated shuttles in the public transport of European cities: The case of the AVENUE project.
}

\author{
Eliane Horschutz Nemoto ${ }^{1,2}$, Ines Jaroudi ${ }^{1,2}$, Guy Fournier ${ }^{1,2}$ \\ ${ }^{1}$ Pforzheim University of Applied Sciences, Tiefenbronner Str. 65, 75175 Pforzheim, \\ Germany \\ ${ }^{2}$ Université Paris-Saclay, CentraleSupélec, Laboratoire Genie Industriel, 3 rue Joliot-Curie, \\ 91190 Gif-sur-Yvette, France.
}

\begin{abstract}
Our current mobility paradigm has reached a tipping point. Individual mobility, based on cheap fossil fuel and high $\mathrm{CO}_{2}$ emissions no longer meet the needs posed by a globally increasing demand for passenger mobility, neither corresponds to the climate agenda.

In this regard, innovations and technologies play an important role to shape the future mobility and provide solutions for more efficient, affordable, accessible, and sustainable mobility in cities.

This paper aims to explore how innovations on mobility, such as shared automated electric vehicles (SAEV) can contribute to a positive change in the mobility paradigm and sustainable mobility, and to this end, which are the current obstacles to be overcome and the key factors related to SAEV's deployment. Thereby, it presents the case of the Autonomous Vehicles to Evolve to a New Urban Experience - 'AVENUE', a European project that has implemented pilot trials to test automated shuttles within the public transport of Lyon, Geneva, Luxembourg, and Copenhagen.

Based on primary data from the project and secondary data from AVENUE public reports, the study reports on the project implementation in the four cities and first learnings through obstacles and key factors to accelerate the deployment of automated shuttles in cities. It contributes to the discussion on technical \& operational, social, and legal obstacles as well as key elements in the deployment of automated shuttles.
\end{abstract}

Keywords: Automated Vehicles, Shared Mobility, Public Transport, Sustainable Mobility.

\section{Introduction}

The nature of mobility is changing. These changes are triggered by the rise of new technologies, new sharing economy models, and the consumer's preference for convenient and flexible mobility without relying on individual cars (Attias, 2017). Such elements call in question the current car-based mobility model.

*Corresponding author at: Tiefenbronner Str. 65, 75175 Pforzheim, Germany.

E-mail address: eliane.horschutz-nemoto@hs-pforzheim.de

https://doi.org/10.1007/978-3-030-61075-3_27 
These transformations have to be aligned and could reinforce the so-called Sustainable Urban Mobility Plans (SUMPs). SUMPs are a new approach to urban mobility planning, that focuses on "sustainable and integrative planning processes", taking into account the adoption of new modes of transport based on micro-mobility, Mobility as a Service (MaaS) and shared transport (Eltis, 2020).

This paper sheds light on the potential changes and transitions on the mobility paradigm triggered by the integration of shared automated electric vehicles (SAEV's) in the public transport of cities, coupled with the discussion on the current obstacles and key factors related to SAEV's deployment (Banister, 2011; Merriman, 2020; Sheller \& Urry, 2016). In this regard, it seeks to answer the following research question: what are the main limitations and key factors for the deployment of SAEV towards sustainable mobility transitions in cities?

To answer this question, the paper relies on the case of the AVENUE, a project operating pilot tests in four European cities - Lyon, Geneva, Luxembourg, and Copenhagen. Key learnings of the first 18 months of the project are now reported on. These reports address obstacles and key factors for the deployment of automated shuttles in European cities and are the basis of this article.

The study combines theoretical research with practical experience from the pilot projects. The methodology applied is qualitative, with an exploratory-descriptive nature (Gil, 2002). Primary data from the project as well as secondary data from public reports of the project were analysed, summarized, presented, and discussed.

Main results and contributions of this study address the technical \& operational, social, and legal obstacles, and respective key factors in the deployment of automated shuttles in cities, as well as, the relation between theoretical reflection and the field experience.

The paper is structured as follows. Section 2 presents the theoretical background, addressing concepts on the mobility paradigm, and transitions to a new and sustainable mobility, as well as concepts on shared, electric and automated mobility, substantiate how they can contribute to future sustainable mobility. Section 3 describes the applied methodology. Section 4 presents the case of the AVENUE project and the test sites. Section 5 presents then the main findings concerning obstacles and key factors to deploy automated shuttles in cities. Section 6 contains the discussions and reflections connecting the theoretical background and results, and section 7 , the concluding remarks.

\section{Theoretical background}

\subsection{The mobility paradigm - concepts and the transition to sustainable mobility}

The discussion addressing the mobility paradigm has raised attention in the last decades, due to the increasing externalities in the transport sector. Indeed, externalities of the transportation sector vary from accidents, congestion, pollution, etc. These costs borne by societies represent a catalyst for a modal shift towards more sustainable and public means of transit (Storchmann, 2003). In the EU for instance, the transport sector is responsible for $27 \%$ of the total greenhouse gas emissions (GHG) in 2017 (European 
Environment Agency, 2019). Globally, the transport sector represents $14 \%$ of the total anthropogenic GHG emissions (IPCC, 2014).

The current mobility paradigm is based on individual mobility, characterized by car ownership, individual rides, cheap fossil fuel, and consequently high $\mathrm{CO} 2$ emissions (Fournier, 2017). This model has influenced how cities and streets are planned, infrastructure is built, and policies are designed.

Merriman (2020) describes a 'new mobility paradigm', which, first, addresses 'the significance of mobility and mobilities in the modern world; and second, but less commonly, the emergence of new forms of mobile practice and technology which are reconfiguring social and economic life".

Sheller and Urry (2016) state that the new mobility paradigm presents intersections among public policy, planning, and applied research, and it plays a role in recognizing the complexity embedded in mobility systems.

Further, Sheller and Urry (2016) refer to a shift towards a "new mobility paradigm" that is occurring nowadays lead by sharing, connectivity, and accessibility. These are socio-technical transitions aiming to decrease the use of automobiles and preparing for a post-auto mobility transition.

Regarding this transition, Banister $(2008,2011)$ sustains that sustainable mobility provides an alternative paradigm to investigate the complexity of cities. He proposes four types of actions towards a 'sustainable mobility paradigm', being: i) Reducing the need to travel - substitution; ii) Transport policy measures - modal shift; iii) Land-use policy measures - distance reduction; iv) Technological innovation - efficiency increase. The author also reinforces the importance of a transition process that involves the support of all stakeholders.

In this paper, the focus is given to the technological, social, and legal aspects of SAEV's, in order to contribute to a transition to a new mobility paradigm.

\subsection{Shared Automated Electric Vehicles (SAEV) - technologies for the transition to a new mobility paradigm}

Shared automated electric vehicles represent a disruptive potential on mobility, by combining shared mobility, electrification, and automation (Sprei, 2017). Such a technology combination has the potential to tackle mobility externalities and contribute to a transition for a sustainable mobility paradigm.

Automated vehicles are vehicles equipped with automated driving systems (ADS) to support or replace human driving, with six levels of driving automation, from Level 0 - no driving automation to Level 5 - full driving automation (SAE, 2018). In this article when referring to 'automated vehicles', it refers to Level 3, Level 4, and Level 5 of driving automation as it was defined by the On-Road Automated Driving committee, 2018.

Automated driving has been seen beneficial to improve mobility safety and avoid accidents, improve the traffic flow and reduce traffic jams, and improve accessibility for instance for elderly people and people with reduced mobility (Litman, 2019). Its benefits can be broadened when combined with shared and electric mobility. 
Shared mobility services, such as car-sharing, ride-sharing, and on-demand ride services, have had a transformative impact on mobility in cities. It enables flexibility, convenience, mobility service customization, and cost savings on mobility (Narayanan, Chaniotakis, \& Antoniou, 2020). Besides its contribution to reducing private vehicle usage, and the modal shift from vehicle ownership to shared mobility services (Shaheen \& Chan, 2015).

Hand (2017) explores the potential of automated vehicles and shared mobility to reshape our cities. In the sense that such combination can contribute to eliminate parking spaces in cities, prioritize space for walking, biking and shared mobility, and alleviate pressures on the built environment.

The study from Jones and Leibowicz (2019) investigated the benefits from the diffusion of shared automated vehicles associated with electrification, proving to be beneficial to reduce mobility greenhouse emissions and to boost renewable electricity generation.

The study from Antonialli (2019) focuses more specifically on shared automated electric shuttles that provide services on public transportation. The study points to 92 experimentations worldwide providing first and last mile itineraries and micro transit commute, with shuttles running in closed or controlled areas or mixed traffic routes. Such experimentations present legal and technological constraints, nonetheless they represent a step forward to understand shared mobility, electrification, and automation can contribute to sustainable mobility in cities.

Further, as pointed out by Sprei (2017), besides new technologies, suitable regulations and policies are crucial for the transition to sustainable mobility, as well as to avoid potential rebound effects.

Shared automated vehicles belong to an array of new technologies that address mobility gaps and provide Mobility-as-a-Service solutions. Thus, SAEV's present an opportunity to reduce automobile use and to reduce pollution. In order to further advance this technology, it is crucial to acknowledge the difficulties encountered in the field tests and provide targeted solutions.

\section{$3 \quad$ Methodology}

This study combines theoretical research with the practical experience from pilot projects deploying automated shuttles in the public transport of European cities. Initially, a literature review provided concepts on the mobility paradigm, and the transitions to a new mobility paradigm and sustainability, as well as concepts on shared automated electric vehicles, its deployment and potential contributions to sustainable mobility in cities.

In order to answer the research question - what are the main limitations and key factors for the deployment of SAEV towards sustainable mobility transition in cities? - the paper relies on the AVENUE project. Primary data were collected based on the learnings of the first 18 months of the project. These learnings address obstacles and 
key factors to accelerate the implementation of automated shuttles, focusing on technical \& operational, social, and legal issues. In addition, secondary data from public reports of the project were analysed, summarized, presented, and discussed.

Studies on environmental and economic impacts, as well and surveys to assess the social impacts of automated shuttles integration on public transport are in the scope of AVENUE project and ongoing. However, due to their early stage, their results are not available yet and not in the scope of this paper.

\section{The case of the AVENUE project}

The focal point of this paper relies on the case of AVENUE - Autonomous Vehicles to Evolve to a New Urban Experience, a Horizon 2020 EU project. It aims to promote public transport services in urban and suburban areas through the deployment of new technologies. The project deploys a fleet of automated electric shuttles in four European cities: Lyon, Copenhagen, Luxembourg, and Geneva (see table 1). The full-scale demonstrations will run for 4 years, from 2018 to 2022.

AVENUE focuses on door-to-door, MaaS solutions, and personalized mobility services, targeting a shift from individually-owned vehicles to sustainable transportation. Such a project presents a plethora of opportunities to test and enhance the services of AV's within the urban public transport network.

Table 1 summarizes information about the different sites and environments where the automated shuttles have been deployed and operational details.

Table 1. The AVENUE pilots test

\begin{tabular}{|c|c|c|c|}
\hline City & Pilot & Route - site & Type of passenger \\
\hline \multirow[b]{2}{*}{ Geneva } & $\begin{array}{l}\text { Meyrin } \\
\text { area }\end{array}$ & $\begin{array}{l}\text { Fixed circular line (route } 2,1 \mathrm{~km} \text { ) } \\
\text { Open road, mixed traffic }\end{array}$ & Resident of the area \\
\hline & Belle-Idée & $\begin{array}{l}\text { Hospital } / \text { Private area } \\
\text { Speed limit } 30 \mathrm{~km} / \mathrm{h} \\
\text { Mixed traffic, to be on demand }\end{array}$ & $\begin{array}{l}\text { Visitors of the hospital, } \\
\text { patients }\end{array}$ \\
\hline Lyon & $\begin{array}{l}\text { Groupama } \\
\text { Stadium }\end{array}$ & $\begin{array}{l}\text { Public, open road (route } 1,3 \mathrm{~km} \text { ) } \\
\text { connects the tramway line with } \\
\text { Groupama stadium }\end{array}$ & $\begin{array}{l}\text { Different passengers, } \\
\text { people with reduced } \\
\text { mobility }\end{array}$ \\
\hline Copenhagen & Nordhaven & Industrial port & not applicable \\
\hline \multirow{2}{*}{ Luxembourg } & Contern & $\begin{array}{l}\text { Industrial area (route } 2,2 \mathrm{~km} \text { ) } \\
\text { Speed limit } 50 \mathrm{~km} / \mathrm{h} \\
\text { Open road, mixed traffic }\end{array}$ & $\begin{array}{l}\text { Employees working at } \\
\text { Campus Contern }\end{array}$ \\
\hline & Pfaffenthal & $\begin{array}{l}\text { Urban area (route } 1,2 \mathrm{~km}) \\
\text { Speed limit } 30 \mathrm{~km} / \mathrm{h} \\
\text { Open road, mixed traffic }\end{array}$ & $\begin{array}{l}\text { Workers, tourists, resi- } \\
\text { dents, and visitors of } \\
\text { Luxembourg city }\end{array}$ \\
\hline
\end{tabular}


The automated shuttles have a capacity of 15 passengers, run in urban and suburban areas, and most of them operate in open roads with mixed traffic. The ride is free of charge, and the speed varies between $11-18 \mathrm{~km} / \mathrm{h}$. Currently, all automated shuttles follow a specific itinerary with fixed routes, although, one of the biggest ambitions of the project is to offer mobility on-demand on a specific area, as the example of Belle Idée in Geneva.

The automated shuttle service provides first and last mile connections on journeys not covered by public transport, or complementing the service intervals offered by public transport, as occurs in Groupama Stadium, in Lyon.The pilots are diverse as they run in different settings. For instance, Contern and Nordhaven are industrial areas whereas Belle idée is a hospital area. The user public varies between employees, tourists, and local residents.

\section{$5 \quad$ Findings and results}

This section presents the learnings of the AVENUE project by addressing the obstacles and pointing key factors to accelerate the implementation and deployment of automated vehicles in the public transport of European cities.

The findings focus on four domains: technical \& operational, social, and legal. It is important to notice that the findings on technical \& operational obstacles present the Public Transport Operators' (PTO's) experience. These reports describe the operational management and the difficulties perceived, therefore, these obstacles are contextbased-cases.

\subsection{Technical \& Operational obstacles and key factors for deployment}

The main obstacles concerning the technical capabilities of the shuttle and its operational performance to provide first and last-mile journeys within the AVENUE test trials are presented in Table 2. They inhibit a full level 4 automation. To better understand the obstacles, they are classified based on the classic 'Sense - Plan - Act' design: a robotics and automation method. To sense means the shuttle is capable of determining its location, perceiving relevant static and dynamic objects, and predicting the future behavior of relevant objects in its environment. To plan means to ensure a collisionfree and accurate driving that respects regulations. To act means to correctly execute the driving plan and to communicate with other road users (Wood et al., 2019; Haag, 2018). Moreover, the infrastructure and consequent operational restrictions faced by the Public Transport Operators are presented as well.

Subsequently, the key factors to overcome such obstacles are addressed in the text. The following findings and information relied on AVENUE public reports. 
Table 2. Technical and resulting operational obstacles

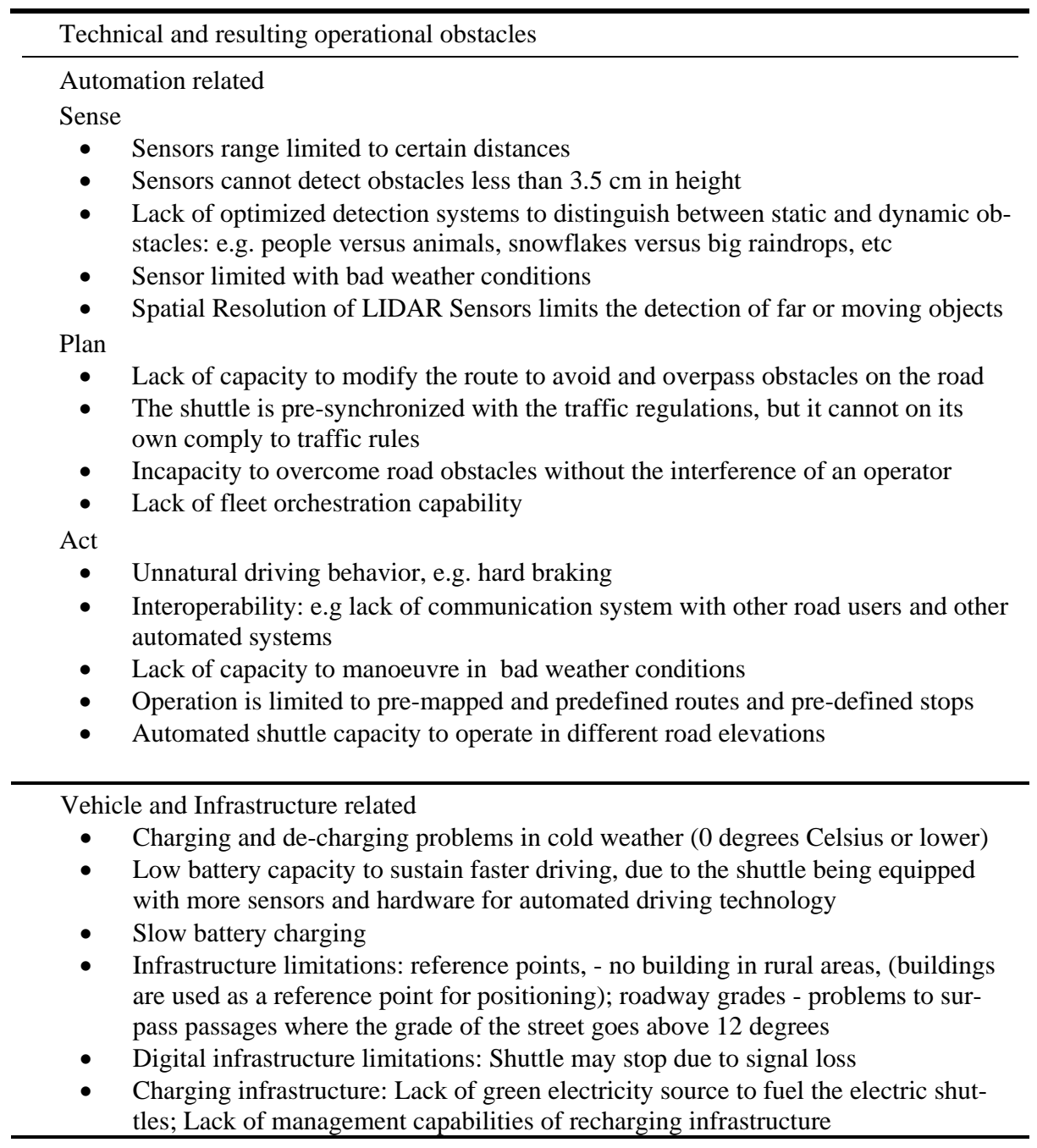

Resulting operational obstacles for the Public Transport Operators (PTO's)

- Mapping and routes: operation limited to predefined routes with involvement from the shuttle provider; Low speeds affect the other road users; Weather limits the operation of the shuttles;

- Maintenance: the provider is responsible for maintaining the shuttles which lead to prolonged delays to operate the shuttles back

- Transport planning: automated shuttles are not integrated into the public transport ecosystem; Lack of means/algorithms to count passengers to estimate occupancy and capacity of passengers inside the shuttle

Source: Elaborated by the authors, based on Bürkle, 2019; Zinckernagel et al., 2018; Zinckernagel et al., 2019; Beukers, 2019; Guldmann et al., 2019; Reisch, 2019; Zuttre, 2019. 
Currently, such obstacles hinder the full operation and full performance of the automated shuttles. Key factors to overcome the automation-related obstacles described in the 'Sense-Plan-Act' are related to improvements on Hardware and Software components, in more details:

i) Improvements of Hardware - such as cameras, radars, sensors resolution, LiDAR, and GPS, for a better capacity to read the environment

ii) Improvements of Software - developing algorithms for perception and object analysis, in order to detect and classify objects and obstacles in the environment; mechanisms for prediction of movements and actions by other motorized and non-motorized moving objects; greater data power processing.

Such improvements would boost the capacity of the automated shuttle to read and interact with the environment, drive faster and more fluidly, distinguish obstacles on the road and bypass it without the manual control, and operate on bad weather conditions. However, the research and development of these new technologies take time and are costly. For instance, the hardware components are limited by a few suppliers, and the technology required is not available on the market or is too expensive (Bürkle, 2019). And a more powerful powertrain would enable the shuttle to operate in hilly conditions and higher road elevations.

Regarding the 'Vehicle and Infrastructure related' obstacles, improvements on the battery capacity and endurance will be necessary in the future for longer performance and to provide mobility on demand.

In the future, it will be key factors $5 \mathrm{G}$ Networks for data transmission and the interoperability of the automated shuttles with other automated systems, as well as with infrastructure and non-automated systems (Zinckernagel et al., 2019).

The support and investment from the cities that host the pilot projects are also key points for coordination and investments on infrastructure to provide and build together connected electric and green mobility.

Most of the operational obstacles faced by the PTO's in the field would be solved by tackling the previous obstacles addressed. In addition, deploying a fleet orchestration platform will be also a crucial tool, when considering the services management, coordination, and maintenance of automated shuttle fleets. For mobility on demand, developing algorithms to estimate the shuttles occupancy and capacity left out is an important point.

According to Bestmile, a partner in the project, fleet orchestration here refers to a broader meaning than fleet management. In the sense that fleet orchestration is not limited just to telematics and preventative maintenance. It is also about coordinating a demand-responsive transit, aiming the operator efficiency, passenger convenience, and benefits for the city traffic (Mellano, 2019).

\subsection{Social obstacles and key factors for deployment}

Social acceptance towards new technologies, human behavior, and interaction with these technologies are also major points for automated driving deployment and diffusion. These social obstacles are here classified based on accessibility and People with 
Reduced Mobility (PRM) accessibility, safety, security, and users' perceptions and acceptance.

Thus, it is discussed here below the social barriers and obstacles facing the deployment of the automated shuttles. The information here presented is based on AVENUE public reports (see summary in table 3 ).

Table 3. Social obstacles

\begin{tabular}{|c|c|}
\hline \multicolumn{2}{|c|}{ Social obstacles } \\
\hline $\begin{array}{rr}\text { Accessi } \\
-\quad \mathrm{B} \\
-\quad \mathrm{e} \\
\mathrm{A} \\
\mathrm{n}\end{array}$ & $\begin{array}{l}\text { ibility and PRM accessibility } \\
\text { Barriers related to the use of technology can exclude certain population groups, } \\
\text { e.g.: elderly people or people not familiar with smartphones and applications } \\
\text { Accessibility and usability for disabled people, e.g. adjust on the vehicle are } \\
\text { needed for people on wheelchair }\end{array}$ \\
\hline $\begin{array}{ll}\text { Safety } \\
-\mathrm{P} \\
-\mathrm{S} \\
-\mathrm{V} \\
-\mathrm{n} \\
-\mathrm{R} \\
-\mathrm{T}\end{array}$ & $\begin{array}{l}\text { Passengers want to talk to a driver and rely on a driver to help them } \\
\text { Stories about accidents with automated vehicles } \\
\text { Worries that other road users will not be able to anticipate the behavior of auto- } \\
\text { mated vehicles } \\
\text { Road users are not used to automated shuttles on the road } \\
\text { The automated shuttle is overtaken by other road users (cars, buses, trucks) }\end{array}$ \\
\hline $\begin{aligned} \text { Security } \\
\bullet \quad \mathrm{R}\end{aligned}$ & $\begin{array}{l}\text { y } \\
\text { Risk of cyber-attacks: hackers could take control of AV's; }\end{array}$ \\
\hline $\begin{array}{ll}\text { Users' } & \mathrm{P} \\
- & \mathrm{T} \\
- & \mathrm{D} \\
- & \mathrm{R} \\
- & \mathrm{A} \\
- & \mathrm{O} \\
\mathrm{P} \\
\mathrm{n} \\
\mathrm{V} \\
\mathrm{tl} \\
\mathrm{tl}\end{array}$ & $\begin{array}{l}\text { Perceptions and Acceptance } \\
\text { The traffic situation is very complex to be handled by technology } \\
\text { Doubts that the technology is mature enough to be trusted } \\
\text { Recent news about accidents with automated vehicles } \\
\text { Automated vehicles will lead to more delays and failures and more traffic jams for } \\
\text { other road users } \\
\text { Passengers do not like the idea that there could be no operator aboard the auto- } \\
\text { mated shuttle, (e.g: to perform first aid, to have an authority figure present, risk of } \\
\text { vandalism, robberies or assaults, no information or support of a supervisor during } \\
\text { the trip if required, no support to reach a connection, no support to get on and off } \\
\text { the shuttle) }\end{array}$ \\
\hline
\end{tabular}

To tackle part of the social obstacles mentioned, a key factor is the presence of an operator on board the shuttle. For the shuttles' deployment, it is required by law, but also according to the AVENUE findings, the operator plays a role in acceptance. It is a major point for people to feel safe, to explain the technology, to provide information, to have a supervising element, and to help elderly people and people with reduced mobility to use the vehicle (Mathé, Dubielzig, \& Lindemann, 2019).

Trust-building measures and the creation of awareness about automated driving technology are necessary (Dubielzig, Reisch, \& Panou, 2018). In this direction, it is recommended to make use of videos and flyers to explain how the technology works and to report real data from the pilot project for the general public. For example about 
the number of passengers that have travelled on the shuttles and/or number kilometers driven to demonstrate the progress of the technology.

Also, it is important to create awareness of road users about the pilot test and automated vehicles, in order to respect the speed of the local roads and the shuttles' speed. In addition, to implement adjustments inside the vehicle to meet the needs of the different people with reduced mobility is a major point to improve the accessibility of the shuttles.

\subsection{Legal obstacles and key factors for deployment}

To advance the deployment of automated shuttles, the legal framework has to adapt accordingly. The insights gathered in this section were collected from the AVENUE public reports (see table 4):

Table 4. Legal obstacles

\begin{tabular}{l}
\hline Legal obstacles \\
• Homologation (technical inspections and documentation) \\
• Legal guidelines: there are no dedicated laws designated for automated driving projects \\
(liability, interoperability, pollution restrictions, data safety) \\
• Institutional development and innovation: Fragmented European collusion and laws con- \\
cerning AV projects.
\end{tabular}

Source: Elaborated by the authors, based on Beukers, 2019; Guldmann et al., 2019; Reisch, 2019; Zuttre, 2019; Bürkle, 2019; Attias, Mira Bonnardel \& Couzineau, 2018.

The territorial jurisdictions vary between France, Switzerland, Luxembourg, and Denmark. The legal procedures depend on the political will to promote new innovative mobility solutions. For instance, Swiss and Luxembourgish authorities are supportive of future transport modes (Reisch, 2019; Beukers, 2019). Regarding the technical inspections and documentation- "the homologation phase" -, the pilot administrators needed to apply for different permissions, especially, if there are alterations needed for the test sites. In Copenhagen, the process requires a third party (an engineering firm) to weigh in on the feasibility and risks of usual transportation projects (Guldmann et al., 2019)

Another obstacle refer to the fact that these projects are pioneers. Therefore, there are no legal guidelines designated for them. So, the project has to adhere to other transportation and infrastructure requirements that are not suitable for the technological and experimental level. This could lead to discordant development. Due to the lack of legal precedents, there are no specific liability clauses about whom takes responsibility in case of an accident, e.g. the need for a driver's license is an open question (Bürkle, 2019). For now, the operators onboard have to possess a valid driving license.

Interoperability defines a struggle also for the lack of precedent of connected systems. Another hurdle that presented itself is data safety and the European restrictions on the matter. As stated in the First report on regulatory requirements: "European 
action on the development of automated and connected vehicles is particularly important... in the field of data access and exchange, to ensure the interoperability of services and interfaces, ensuring security and privacy" (Couzineau et al., 2018).

Partners presented key factors to deploy the shuttles successfully in their project deliverables. Keolis emphasized the need for starting new projects of AV's in order to advance the technology and garner political support. They also pointed out that public transport operators have to provide technical transparency communication and admit the challenges facing AV's projects (Zuttre, 2019).

Moreover, there is a need for uniform and specific guidelines for AV's pilots (Guldmann et al., 2018). This could be agreed upon through a joint EU-based AV law department that, centrally, can ensure state-of-the-art knowledge regarding type approvals. In this case, not only type approvals of the vehicles but also approvals of routes and software across EU borders - one legal framework to accommodate all approvals necessary to implement AV's. Most importantly, one department with the ability to constantly update the legal framework to ensure safety and agile development of AV.

\section{Discussion}

The results, although from an incipient phase of the project, show the current stage of SAEV's performance and services within the public transport of European cities. The technological and operational obstacles require continuous improvements, and for this, regular feedback from the field is valuable to guide the advances in technology and services. To a certain extent, the performance of the SAEV's may furthermore influence social acceptance and legal developments. For social acceptance, the pilot projects are a good start for users to get familiar and build trust towards autonomous driving, and evaluate the usability of SAEV's. The project contributes this way to the diffusion of innovation towards sustainable urban mobility. In addition, the pilot projects provide relevant legal recommendations envisioning to build a common background for standards, regulations, and one legal framework for AV's in Europe.

Except for some technological improvements, many of the obstacles and key factors pointed in this paper concern consequently a process of medium and long-term goals for SAEV's to be ready to be deployed on-demand and on a broader scale in cities. Furthermore, it may be a long-term process for AV's to bring real impacts to the current mobility paradigm as stated by Jones and Leibowicz (2019) and Shaheen and Chan (2015), by replacing journeys with individual cars, favoring shared and electric powertrain, and reducing mobility externalities.

However, as suggested by Banister $(2008,2011)$, the AVENUE project contributes to introducing innovating transport systems to better satisfy the transport needs of passengers to a transition towards sustainable mobility and a new mobility paradigm.

It is also important to note that these new trends add more complexity to mobility and that technology per se will not solve the problem. Therefore, future mobility requires more common efforts to strengthen the intersections among mobility planning, governance, policies, and regulations that contextualize the use of technology, as 
pointed by Sheller and Urry (2016). In addition, SAEV's may be deployed in consistency with other soft modes of transport, considering for instance that more walkable spaces and cycling lines are aspirated in cities, therefore, as stated by Hand (2017), AV's technologies could be an enabler to reshape cities and alleviate pressures on the built environment.

\section{Conclusion}

Based on the case of the AVENUE project, this paper presents how the pilot projects have performed within diverse contexts testing automated shuttles in four European cities. The AVENUE project reveals that automated shuttle services can provide solutions to mobility gaps on a local scale where there is no public transport (or still weak public transport service). Further, once deployed on a broader scale, SAEV's could also contribute to changes in the mobility paradigm by replacing journeys with individual cars with shared mobility, fostering electric powertrain, and tackling mobility externalities for sustainable mobility in cities.

The obstacles and key factors in the deployment of SAEV presented and discussed may entail a process of medium and long-term for technology improvements and tests, social acceptance and familiarization with the technology, and legal support. In addition, the transition to a new and sustainable mobility paradigm will require to take into perspective the complexity of mobility and all its intersections.

In this regard, projects like AVENUE play an important role in setting new mobility ecosystems and the ground for manufacturers, software developers, and transport operators to work together to diversify and innovate the mobility system to provide more convenient and sustainable public transport.

It raises awareness among citizens and road users on a city scale level about automated driving, and it provides relevant findings of the citizens' willingness and positioning towards this technology. This sort of project pushes the boundaries of existing legal frameworks. It requires collective action that lies down solid regulatory foundations that promote sustainable, accessible, and affordable mobility. By drafting adequate regulations, mobility innovations could thrive while meeting the community's and the city's needs.

To conclude, the pilot tests can be seen as a preparation for the transition for the mobilities of the future, aiming to contribute to a more sustainable mobility paradigm, based on shared, electric, and automated mobility.

Disclaimer: The research leading to these results has received funding from the European Union's Horizon 2020 research and innovation program under grant agreement No. 769033, for the AVENUE project. 


\section{References}

Attias, D. (2017). The Automobile World in a State of Change: From the Automobile to the Concept of Auto-Mobility. In The Automobile Revolution. Switzerland: Springer International Publishing. https://doi.org/10.1007/978-3-319-45838-0_2

Banister, D. (2011). Cities, mobility and climate change. Journal of Transport Geography, 19(6), 1538-1546. https://doi.org/10.1016/j.jtrangeo.2011.03.009

Beukers, J. (2019). First Iteration Geneva Large Scale Pilot Use Case Demonstration Report: AVENUE project.

Bürkle, T. (2019). Autonomous Shuttles: Technical Obstacles for the Diffusion, Implementation and the Deployment.

Denmark, D. (1998). The Outsiders: Planning and Transport Disadvantage. Journal of Planning Education and Research, 17(3), 231-245. https://doi.org/10.1177/0739456X9801700304

Dubielzig, M., Reisch, M., \& Panou, M. (2018). First Passenger needs analysis and specifications: AVENUE project.

Eltis (2020). The SUMP Concept and Guidelines. Retrieved from https://www.eltis.org/mobility-plans/sump-concept

European Environment Agency (2019). Greenhouse gas emissions from transport in Europe. Retrieved from https://www.eea.europa.eu/downloads/7009a89effc04dbea8b5f94ff0a39912/1576584662/transport-emissions-of-greenhouse-gases-12.pdf

Fournier, G. (2017). The New Mobility Paradigm. Transformation of Value Chain and Value Proposition Through Innovations (Attias D. (eds) The Automobile Revolution): Springer. https://doi.org/10.1007/978-3-319-45838-0_3

Guldmann, S., Zinckernagel, C., \& Lytzen, P. (2019). First iteration Copenhagen Large Scale Pilot Use Case Demonstration report: AVENUE project.

Haag, A. (2018). State of the Art in Autonomous Driving. Retrieved from https://events.techcast.com/btd/2018/Sydney_1005/

Hand, A. (2017). Redefining Urban Mobility: Four Ways Shared Autonomous Vehicles Will Reshape Our Cities, Real Estate Issues, Spring, pp.49-52.

Harper, D. (2020). Paradigm: Origin and meaning of paradigm. Retrieved from https://www.etymonline.com/word/paradigm

IPCC (Ed.) (2014). Climate change: Mitigation of climate change Working Group III contribution to the Fifth Assessment Report of the Intergovernmental Panel on Climate Change. New York NY: Cambridge University Press.

Jones, E. C., \& Leibowicz, B. D. (2019). Contributions of shared autonomous vehicles to climate change mitigation. Transportation Research Part D: Transport and Environment, 72, 279-298. https://doi.org/10.1016/j.trd.2019.05.005

Litman, T. (2019). Autonomous Vehicle Implementation Predictions Implications for Transport Planning.

Mathé, L., Dubielzig, M., \& Lindemann, M. (2019). Second Passenger needs analysis and specifications: AVENUE project.

McKay, J. (2019). Transport or Mobility: What's the difference and why does it matter? Retrieved from https://www.forumforthefuture.org/blog/transport-or-mobility

Mellano, A. (2019). Fleet orchestration: keys to successful AV mobility service. Retrieved from https://www.autonomousvehicletech.com/articles/1879-fleet-orchestration-keys-tosuccessful-av-mobility-service 
Merriman, P. (2020). Mobility. International Encyclopedia of Human Geography, 141-148. https://doi.org/10.1016/B978-0-08-102295-5.10292-6

Narayanan, S., Chaniotakis, E., \& Antoniou, C. (2020). Shared autonomous vehicle services: A comprehensive review. Transportation Research Part C: Emerging Technologies, 111, 255-293. https://doi.org/10.1016/j.trc.2019.12.008

Reisch, M. (2019). First Iteration Luxembourg Large Scale Pilot Use Case Demonstration Report: AVENUE project.

SAE (2018). Taxonomy and Definitions for Terms Related to Driving Automation Systems for On-Road Motor Vehicles. Retrieved from https://saemobilus.sae.org/content/J3016_201806

Shaheen, S., Chan, N. (2015). Mobility and the sharing economy: Impacts synopsis. Retrieved from http://innovativemobility.org/wp-content/uploads/Innovative-Mobility-Industry-Outlook_SM-Spring-2015.pdf

Shannon, T. (2006). The ethics of mobility: a framework for assessing mobility paradigms, 569-578. https://doi.org/10.2495/SC060541

Sheller, M., \& Urry, J. (2016). Mobilizing the new mobilities paradigm. Applied Mobilities, 1(1), 10-25. https://doi.org/10.1080/23800127.2016.1151216

Sprei, F. (2017). Disrupting mobility. Energy Research \& Social Science, 37, 238-242. https://doi.org/10.1016/j.erss.2017.10.029

Wood et al. (2019). Safety first for automated driving. Retrieved from https://www.aptiv.com/docs/default-source/white-papers/safety-first-for-automated-driving-aptiv-whitepaper.pdf

Zinckernagel, C., Guldmann, S., \& Lytzen, P. (2018). First Gap analysis and recommendations on autonomous vehicles for public service: AVENUE project.

Zinckernagel, C., Lutgens, E., Guldmann, S., \& Lytzen, P. (2019). Second Gap analysis and recommendations on autonomous vehicles for public service: AVENUE project.

Zuttre, Q. (2019). First iteration Keolis Lyon Large Scale Pilot Use Case Demonstration Report: AVENUE project. 